\title{
Theoretical Study of the Electronic Spectrum of Disulfur Monoxide
}

Carlos J. Cobos and Adela E. Croce

The Research Institute of Theoretical and Applied Physical Chemistry, Department of Chemistry, Faculty of Exact Sciences, National University of La Plata, Casilla de Correo 16, Sucursal 4, (1900) La Plata, Argentina

Reprint requests to A. E. C.; E-mail: acroce@ inifta.unlp.edu.ar

Z. Naturforsch. 69a, 215 -219 (2014) / DOI: 10.5560/ZNA.2014-0009

Received October 29, 2013 / revised February 5, 2014 / published online April 2, 2014

The near ultraviolet-visible absorption spectrum of disulfur monoxide $\left(\mathrm{S}_{2} \mathrm{O}\right)$ has been theoretically studied by using the time-dependent density functional theory (TD-DFT) and the equation of motion coupled-cluster singles and doubles approach (EOM-CCSD) combined with the AUG-cc-PVQZ basis set. From this, analytical expressions for the absorption coefficient over the $250-340 \mathrm{~nm}$ range are reported for the first time. The computed molecular structure and the vibrational frequencies for the ground and third electronically excited state $\mathrm{S}_{2} \mathrm{O}\left(\mathrm{C}^{1} \mathrm{~A}^{\prime}\right)$, responsible of the observed spectrum, are compared with available data.

Key words: $\mathrm{S}_{2} \mathrm{O}$; Absorption Spectra; TD-DFT; EOM-CCSD.

\section{Introduction}

In addition to the well identified sulfur dioxide $\left(\mathrm{SO}_{2}\right)$ molecule, the presence of disulfur monoxide $\left(\mathrm{S}_{2} \mathrm{O}\right)$ has been proposed to explain some relevant spectral features of the surface of Io, Jupiter's moon. Modelling calculations suggest the formation of up to $6 \%$ of $\mathrm{S}_{2} \mathrm{O}$ from equilibrated $\mathrm{SO}_{2} / \mathrm{S}_{2}$ mixtures near the volcanoes of Io [1]. This species also participates in the Venus sulfur chemistry, which determines the composition of the middle atmosphere [2]. The sulfur oxide obtained by streaming $\mathrm{SO}_{2}$ at low pressure through a high voltage electric discharge [3] is at present known as disulfur monoxide $\mathrm{S}_{2} \mathrm{O}[4,5]$. The electronic absorption spectrum [6-10] has been investigated in detail. The $\mathrm{S}_{2} \mathrm{O}$ exhibits two absorption regions, one extending from 250 to $340 \mathrm{~nm}$, and the other from 190 to $230 \mathrm{~nm}$. In particular, the first region presents an intense and richly-structured absorption band picket at about $295 \mathrm{~nm}$. Although vibrational analysis studies of this band have been reported [6-10], surprisingly no absorption coefficient data are available. Due to the fact that this information is relevant for future photochemical, kinetic, and modelling studies of planetary importance, a theoretical study on the basis of the complete near-UV spectrum of $\mathrm{S}_{2} \mathrm{O}$ measured by Phillips et al. [8] has been undertaken.

\section{Computational Methods}

Electronic excitation energies of valence excited states which can be described by combinations of single one electron transitions can be reasonably well described by the time-dependent density functional theory (TD-DFT) theory. However, due to the fact that a mathematical expression for the real exchange-correlation functional in DFT is unknown [11], a large number of specific and general approaches have been proposed. For this reason, different formulations are usually employed and the resulting data are normally confronted with experiments. In this study the following hybrid funtionals were employed: B3LYP, O3LYP, X3LYP, B1LYP, mPW1LYP, B3PW91, B97-2, B98, PBE1PBE, mPW1PW91, BMK, M06-2X, tHCTHhyb, wB97XD, CAM-B3LYP, and HSEh1PBE. In addition, the excitation energies were computed using the state-of-the-art equation of motion coupled-cluster singles and doubles method (EOM-CCSD). For all models the large AUGcc-pVQZ basis set was used [12]. The present EOMCCSD calculations are based on B3LYP optimized geometries. All mentioned methods are implemented in the employed Gaussian suite of programs [13].

\section{Absorption Spectrum}

The $\mathrm{S}_{2} \mathrm{O}$ absorption spectrum of $\mathrm{S}_{2} \mathrm{O}$ trapped in a xenon matrix at $20 \mathrm{~K}$ (up to three units of absorbance 


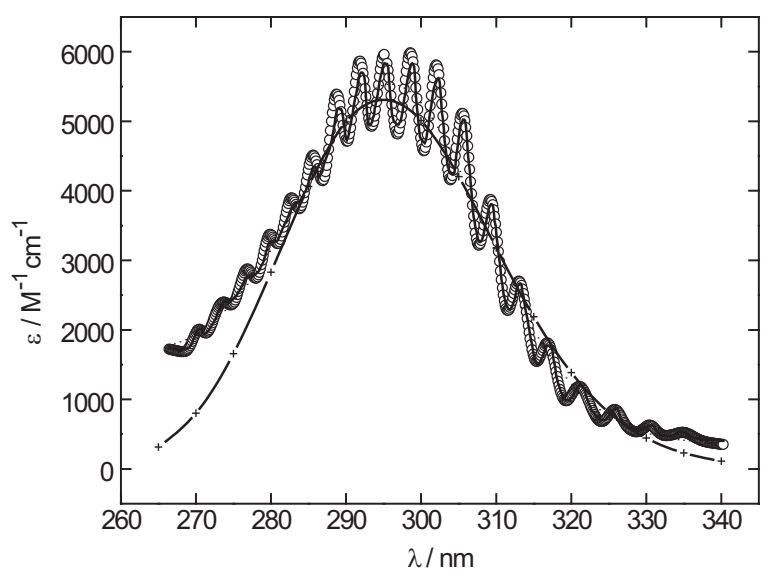

Fig. 1. Comparison between the experimental and computed ultraviolet-visible spectrum of $\mathrm{S}_{2} \mathrm{O}$. (-): Experiments from [6]; (-+-): Present quantum-mechanical calculations (see text); (०): (2).

scale) is depicted in Figure 1 [8]. The spectrum consists in a single progression of vibrational bands ( $\mathrm{S}-$ $\mathrm{S}$ stretching mode) very similar to the observed in the gaseous phase and at room temperature [6, 7]. It is interesting to note that a recent low temperature matrix spectrum, only limited to the $320-340 \mathrm{~nm}$ range, shows an identical structure for the first four vibrational levels of $\mathrm{S}_{2} \mathrm{O}$ [14]. Our calculations show that to cover the near-UV region of the experimental spectrum, only the third singlet-singlet valence electronic transition of $\mathrm{S}_{2} \mathrm{O}$ is required. In fact, the first two EOM-CCSD electronic transitions, as indicated by the very low oscillator strengths $f$, exhibit negligible intensity and, above the third, the more important transitions are the sixth and the eighth located at $178 \mathrm{~nm}(f=0.0089)$ and $167 \mathrm{~nm}$ $(f=0.0717)$, respectively.

The vertical excitation energies $E_{\mathrm{m}}$, the associated wavelengths $\lambda_{\mathrm{m}}$, the $f$ values, the structural parameters, and harmonic vibrational frequencies for both, the ground and the third electronically excited state are listed in Table 1. Additional TD-DFT calculations carried out with different basis sets lead to essentially similar results. By instance, the alternative use of the 6$311+\mathrm{G}(3 \mathrm{~d} 2 \mathrm{f})$ Pople's basis set [15], of the AUG-ccpVQZ basis set with the inclusion of tight d-functions or 2df-functions, or even of the larger AUG-cc-pV5Z basis set does not affect $\lambda_{\mathrm{m}}$ and $f$ significantly. In fact, the resulting values obtained with the B3LYP functional are: $\lambda_{\mathrm{m}}=284 \mathrm{~nm}$ and $f=0.0646(6-311+\mathrm{G}(3 \mathrm{~d} 2 \mathrm{f}))$; $\lambda_{\mathrm{m}}=284 \mathrm{~nm}$ and $f=0.0644$ (AUG-cc-pV(Q+d)Z); $\lambda_{\mathrm{m}}=284 \mathrm{~nm}$ and $f=0.0642$ (AUG-cc-pV(Q+2df)Z); and $\lambda_{\mathrm{m}}=288 \mathrm{~nm}$ and $f=0.0640$ (AUG-cc-pV5Z). As Table 1 shows, these values are in very good agreement with those obtained with the AUG-cc-pVQZ basis set.

Despite the different generation of exchange and correlation funtionals employed, similar results were found and, thus, no approach can be definitely attributed superior to the rest. Therefore, for simplicity, no individual theoretical method is discussed. All data were averaged to facilitate the comparison with available experimental and theoretical data. In this way, the TD-DFT average values of $E_{\mathrm{m}}=4.38 \pm 0.06 \mathrm{eV}\left(\lambda_{\mathrm{m}}=283 \pm 4 \mathrm{~nm}\right)$ and $f=0.0697 \pm 0.005$ were derived. As Table 1 shows, the EOM-CCSD value for the band localization, $4.44 \mathrm{eV}$ $\left(\lambda_{\mathrm{m}}=279 \mathrm{~nm}\right)$, is within the above given deviation. However, the oscillator strength is $\approx 25 \%$ larger than those provided by the TD-DFT methods. The theoretical predictions, when compared with the experimental value of about $4.2 \mathrm{eV}(\approx 295 \mathrm{~nm})$, lead to a center of band position shifted in about $+0.2 \mathrm{eV}$. A similar behaviour has been observed for the three absorption bands of the $\mathrm{CF}_{3} \mathrm{OSO}_{3}$ radical [16]. It should be noted that typical deviations of $0.3-0.4 \mathrm{eV}$ (TDDFT) $[17,18]$ and $0.2-0.3 \mathrm{eV}$ (EOM-CCSD) [18] have been reported for a large number of small- to mediumsized molecules. On the other hand, all computed $f$ values of Table 1 lie in between the notably discrepant values of 0.17 [19] and $\approx 0.026$ [20] derived from measured radiative lifetimes of the $\mathrm{C}^{1} \mathrm{~A}^{\prime}$ state.

The calculations indicate that the largest spin coefficient for the third excited state is $c_{18 \rightarrow 21}=$ $0.670 \pm 0.001$ (average of all employed methods), and corresponds to the excitation from the molecular orbital 18 to the molecular orbital 21 ( $\pi \rightarrow \pi^{*}$ transition located along the S-S bond). The resulting contribution percentage of this configuration is given by $100 \times 2 \times c_{18 \rightarrow 21}^{2}=90 \%$, where the factor 2 accounts for two contributions in a properly spin-adapted eigenfunction.

To a best comparison between experimental and theoretical results, the decadic absorption coefficient $\varepsilon$ (in units $\mathrm{M}^{-1} \mathrm{~cm}^{-1}$ ) over the relevant energy range was calculated as [16]

$\varepsilon \cong 1.15 \cdot 10^{4}\left(\frac{f}{\sigma}\right) \exp \left(-\frac{1}{2}\left(\frac{E-E_{\mathrm{m}}}{\sigma}\right)^{2}\right)$.

Here the band form is represented by a Gaussian function $\varepsilon=\varepsilon_{\mathrm{m}} \exp \left(-\frac{1}{2}\left(\frac{E-E_{\mathrm{m}}}{\sigma}\right)^{2}\right)$, with a full width of the 
band at $\frac{1}{\mathrm{e}}$ height of $\sigma$, and an energy maximum of $E_{\mathrm{m}}$ $=\hbar c / \lambda_{\mathrm{m}}$, where $\hbar$ is Planck's constant and $c$ the velocity of light in a vacuum. As usual, the $\sigma$ parameter was used to match the theoretical and experimental spectra.

To compare the theoretical with the experimental data, the transformation of the absorbances (measurements performed up to three units of absorbance scale [6]) to absorption coefficients is required. However, because neither the optical pathway $l$ as defined by the thickness of the $\mathrm{S}_{2} \mathrm{O}$ deposited in the cryogenic matrix nor the $\mathrm{S}_{2} \mathrm{O}$ concentration $c$ are known, the absorbances were appropriately scaled to transform to absorption coefficients [16]. In fact, an scaling factor of $\frac{1}{l c}=7634 \mathrm{M}^{-1} \mathrm{~cm}^{-1}$ has been recently employed to reproduce over the $220-540 \mathrm{~nm}$ range, the spectrum of the $\mathrm{CF}_{3} \mathrm{OSO}_{3}$ radical deposited in a neon matrix at $6 \mathrm{~K}$ [16]. For the present case, we have modelled the spectrum employing the $f$ value predicted by the EOMCCSD calculations and shifted the computed average $\lambda_{\mathrm{m}}$ of $283 \mathrm{~nm}$ in only $-12 \mathrm{~nm}$ to superpose the maxima values of experimental and theoretical curves. In the absence of a reliable theoretical foundation for the vibrational broadening, the bandwidth $\sigma=0.20 \mathrm{eV}$ and the scaling factor $1950 \mathrm{M}^{-1} \mathrm{~cm}^{-1}$ were employed to account for the spectrum shape. It should be noted that this $\sigma$ value is almost equal to the found for the more complicated three-band spectrum of the $\mathrm{CF}_{3} \mathrm{OSO}_{3}$ radical of $0.21 \mathrm{eV}$ [16].

As Figure 1 shows, neglecting the vibronic structure, the resulting theoretical curve reproduces acceptably well the global contour of the spectrum above

Table 1. Vertical excitation energies, wavelengths, oscillator strengths, $\mathrm{S}-\mathrm{S}$ and $\mathrm{S}-\mathrm{O}$ bond lengths, bond angles, and the corresponding harmonic vibrational frequencies (see text). For all calculations, the basis set AUG-cc-pVQZ was used. Each first line gives the values for the electronically excited state, each second line those for the ground electronic state.

\begin{tabular}{|c|c|c|c|c|c|}
\hline Level of theory & $E_{\mathrm{m}}(\mathrm{eV})$ & $\lambda_{\mathrm{m}}(\mathrm{nm})$ & $f$ & Bond lengths $(\AA)$ and angles $\left({ }^{\circ}\right)$ & Frequencies $\left(\mathrm{cm}^{-1}\right)$ \\
\hline \multirow[t]{2}{*}{ B3LYP } & 4.31 & 288 & 0.0656 & $2.176,1.486,109.1$ & $384,1080,243$ \\
\hline & & & & $1.901,1.465,117.8$ & $682,1182,381$ \\
\hline \multirow[t]{2}{*}{ O3LYP } & 4.38 & 283 & 0.0595 & $2.145,1.490,109.2$ & $400,1065,251$ \\
\hline & & & & $1.895,1.466,118.0$ & $690,1186,381$ \\
\hline \multirow[t]{2}{*}{ X3LYP } & 4.32 & 287 & 0.0666 & $2.171,1.484,108.9$ & $388,1087,245$ \\
\hline & & & & $1.899,1.463,117.7$ & $686,1190,383$ \\
\hline \multirow[t]{2}{*}{ B1LYP } & 4.32 & 287 & 0.0692 & $2.173,1.482,109.0$ & $387,1096,246$ \\
\hline & & & & $1.898,1.462,117.7$ & $690,1196,385$ \\
\hline \multirow[t]{2}{*}{ mPW1LYP } & 4.32 & 287 & 0.0685 & $2.171,1.482,108.9$ & $388,1096,246$ \\
\hline & & & & $1.897,1.461,117.6$ & $690,1198,385$ \\
\hline \multirow[t]{2}{*}{ B3PW91 } & 4.41 & 281 & 0.0673 & $2.140,1.485,108.9$ & $409,1086,255$ \\
\hline & & & & $1.891,1.460,117.7$ & $701,1205,385$ \\
\hline \multirow[t]{2}{*}{ B97-2 } & 4.46 & 278 & 0.0687 & $2.132,1.481,109.0$ & $409,1096,258$ \\
\hline & & & & $1.885,1.457,117.8$ & $712,1215,390$ \\
\hline \multirow[t]{2}{*}{ B98 } & 4.32 & 287 & 0.0670 & $2.171,1.481,109.0$ & $403,1107,250$ \\
\hline & & & & $1.904,1.460,117.7$ & $677,1206,382$ \\
\hline \multirow[t]{2}{*}{ PBE1PBE } & 4.47 & 277 & 0.0702 & $2.124,1.480,108.6$ & $421,1107,261$ \\
\hline & & & & $1.885,1.456,117.7$ & $718,1227,391$ \\
\hline \multirow[t]{2}{*}{ mPW1PW91 } & 4.46 & 278 & 0.0705 & $2.128,1.479,108.8$ & $418,1107,260$ \\
\hline & & & & $1.885,1.455,117.7$ & $715,1226,391$ \\
\hline \multirow[t]{2}{*}{ BMK } & 4.34 & 286 & 0.0742 & $2.149,1.469,108.7$ & $455,1153,267$ \\
\hline & & & & $1.913,1.448,117.5$ & $700,1242,384$ \\
\hline \multirow[t]{2}{*}{ M06-2X } & 4.40 & 282 & 0.0790 & $2.122,1.472,108.4$ & $421,1160,263$ \\
\hline & & & & $1.877,1.450,117.4$ & $730,1263,394$ \\
\hline \multirow[t]{2}{*}{ tHCTHhyb } & 4.33 & 286 & 0.0630 & $2.162,1.486,108.9$ & $400,1079,249$ \\
\hline & & & & $1.903,1.463,117.8$ & $677,1186,378$ \\
\hline \multirow[t]{2}{*}{ wB97XD } & 4.45 & 279 & 0.0788 & $2.125,1.473,108.6$ & $430,1132,267$ \\
\hline & & & & $1.879,1.450,117.5$ & $725,1259,397$ \\
\hline \multirow[t]{2}{*}{ CAM-B3LYP } & 4.40 & 282 & 0.0781 & $2.128,1.474,1.805$ & $417,1129,261$ \\
\hline & & & & $1.878,1.452,117.5$ & $726,1240,396$ \\
\hline \multirow[t]{2}{*}{ HSEh1PBE } & 4.46 & 278 & 0.0695 & $2.128,1.480,108.7$ & $417,1101,259$ \\
\hline & & & & $1.886,1.457,117.7$ & $714,1221,389$ \\
\hline EOM-CCSD & 4.44 & 279 & 0.0935 & - & - \\
\hline
\end{tabular}


$\approx 285 \mathrm{~nm}$. As above mentioned, no relevant electronic transitions are present up to about $6.9 \mathrm{eV}(\approx 180 \mathrm{~nm})$, therefore, the departure from the simple Gaussian shape could be attributed to the well established predissociation within the electronically-excited manifold, leading to ground state $\mathrm{S}$ and $\mathrm{SO}$ species [21].

To practical purposes (i. e., for photochemical and kinetics studies of second-order reactions) realistic values of $\varepsilon$ vs. $\lambda$ are highly desirable. In the absence of direct measurements of the $\mathrm{S}_{2} \mathrm{O}$ absorption coefficient, and on the basis of the above analysis, the spectrum can be accurately fitted by a sum of single Gaussian functions. The resulting function, which accounts for the vibrational structure of the spectrum, is the following:

$$
\begin{aligned}
\varepsilon= & -4.599 \cdot 10^{3}+1.684 \cdot 10^{-1} v \\
& +7.979 \cdot 10^{-1} \sum_{i=0}^{18} \frac{A_{i}}{\omega_{i}} \exp \left(-2\left(\frac{v-v_{i}}{\omega_{i}}\right)^{2}\right),
\end{aligned}
$$

where $v=\frac{1}{\lambda}$. The curve depicted in Figure 1 has been obtained using the $A_{i}, \omega_{i}$, and $v_{i}$ specific coefficients for the $i$ th vibrational state listed in Table 2.

\section{Molecular Structure and Harmonic Vibrational Frequencies}

The extensive band system suggests a substantial geometry change after the electronic excitation to the third

Table 2. State-selected coefficients for (2).

\begin{tabular}{lccl}
\hline $\begin{array}{l}\text { Vibrational } \\
\text { state }\end{array}$ & $A_{i}$ & $\omega_{i}\left(\mathrm{~cm}^{-1}\right)$ & $v_{i}\left(\mathrm{~cm}^{-1}\right)$ \\
\hline 0 & $2.587 \cdot 10^{4}$ & $2.146 \cdot 10^{2}$ & $2.985 \cdot 10^{4}$ \\
1 & $2.307 \cdot 10^{4}$ & $1.385 \cdot 10^{2}$ & $3.026 \cdot 10^{4}$ \\
2 & $6.185 \cdot 10^{4}$ & $1.741 \cdot 10^{2}$ & $3.069 \cdot 10^{4}$ \\
3 & $1.673 \cdot 10^{5}$ & $2.471 \cdot 10^{2}$ & $3.114 \cdot 10^{4}$ \\
4 & $3.007 \cdot 10^{5}$ & $2.241 \cdot 10^{2}$ & $3.155 \cdot 10^{4}$ \\
5 & $6.025 \cdot 10^{5}$ & $2.559 \cdot 10^{2}$ & $3.194 \cdot 10^{4}$ \\
6 & $9.758 \cdot 10^{5}$ & $2.645 \cdot 10^{2}$ & $3.233 \cdot 10^{4}$ \\
7 & $1.413 \cdot 10^{6}$ & $2.751 \cdot 10^{2}$ & $3.273 \cdot 10^{4}$ \\
8 & $1.510 \cdot 10^{6}$ & $2.619 \cdot 10^{2}$ & $3.310 \cdot 10^{4}$ \\
9 & $1.700 \cdot 10^{6}$ & $2.870 \cdot 10^{2}$ & $3.348 \cdot 10^{4}$ \\
10 & $1.790 \cdot 10^{6}$ & $3.058 \cdot 10^{2}$ & $3.389 \cdot 10^{4}$ \\
11 & $1.496 \cdot 10^{6}$ & $2.746 \cdot 10^{2}$ & $3.427 \cdot 10^{4}$ \\
12 & $1.387 \cdot 10^{6}$ & $2.833 \cdot 10^{2}$ & $3.463 \cdot 10^{4}$ \\
13 & $1.145 \cdot 10^{6}$ & $3.024 \cdot 10^{2}$ & $3.502 \cdot 10^{4}$ \\
14 & $8.403 \cdot 10^{5}$ & $2.903 \cdot 10^{2}$ & $3.539 \cdot 10^{4}$ \\
15 & $6.223 \cdot 10^{5}$ & $2.804 \cdot 10^{2}$ & $3.574 \cdot 10^{4}$ \\
16 & $4.992 \cdot 10^{5}$ & $3.089 \cdot 10^{2}$ & $3.612 \cdot 10^{4}$ \\
17 & $3.806 \cdot 10^{5}$ & $3.728 \cdot 10^{2}$ & $3.655 \cdot 10^{4}$ \\
18 & $8.065 \cdot 10^{4}$ & $2.006 \cdot 10^{2}$ & $3.699 \cdot 10^{4}$ \\
\hline
\end{tabular}

electronic state of $\mathrm{S}_{2} \mathrm{O}$. In fact, the light absorption by the $\mathrm{S}-\mathrm{S}$ double bond promotes one $\pi$ valence electron into a virtual antibonding $\pi^{*}$ orbital. As a consequence, the concomitant $\mathrm{S}-\mathrm{S}$ elongation and reduction of the S-S-O angle are expected. Actually, from the resulting DFT structural data listed in Table 1, the following average values were obtained: $r_{\mathrm{S}-\mathrm{O}}=1.480 \pm 0.006 \AA$, $r_{\mathrm{S}-\mathrm{S}}=2.146 \pm 0.021 \AA$, and $\varangle \mathrm{S}-\mathrm{S}-\mathrm{O}=108.8 \pm 0.2^{\circ}$. These values compare very well with the experimental values of $1.50 \AA$ (assumed value), $2.14 \AA$, and $\approx$ $109^{\circ}$ [10], and $1.483 \AA, 2.168 \AA$, and 106 or $110^{\circ}$ [21]. Similar calculations performed for the ground state (see Tab. 1) lead to $r_{\mathrm{S}-\mathrm{O}}=1.458 \pm 0.006 \AA, r_{\mathrm{S}-\mathrm{S}}=$ $1.892 \pm 0.011 \AA$, and $\varangle \mathrm{S}-\mathrm{S}-\mathrm{O}=117.7 \pm 0.1^{\circ}$, in very good agreement, respectively, with the measured data of $1.4594 \AA, 1.8845 \AA$, and $118.08^{\circ}$ [5, 22].

As Table 1 shows, after excitation, the S-S bond weakening yields a marked reduction in the frequency values. The resulting average values for the $\mathrm{S}-\mathrm{S}$ stretching, S-O stretching, and bending modes are: $409 \pm$ $19,1105 \pm 26$, and $255 \pm 8 \mathrm{~cm}^{-1}$ (excited state) and $702 \pm 18,1215 \pm 26$, and $387 \pm 6 \mathrm{~cm}^{-1}$ (ground state). For both electronic states, the $\mathrm{S}-\mathrm{S}$ stretching and bending degrees of freedom agree reasonably well with the infrared values of $405[19,23]$ and $415.2 \mathrm{~cm}^{-1}$ [20], and 252 [19] and $253 \mathrm{~cm}^{-1}$ [23] (excited state) and 679 and $388 \mathrm{~cm}^{-1}$ (ground state) $[5,18,20]$. However, our computed values for the $\mathrm{S}-\mathrm{O}$ stretching overestimates the experimental values of 1030 [19] and $1032 \mathrm{~cm}^{-1}$ [23] (excited state), and $1165 \mathrm{~cm}^{-1}$ (ground state) $[7,22,24]$.

\section{Conclusion}

This study allows to reproduce the observed features of the $\mathrm{S}_{2} \mathrm{O}$ spectrum between 270 and $340 \mathrm{~nm}$ and to transform the absorbance data of [6] on an absolute basis, useful for future kinetics and planetary simulations. Besides, the obtained structural and infrared spectroscopic properties of the $\mathrm{S}_{2} \mathrm{O}\left(\mathrm{C}^{1} \mathrm{~A}^{\prime}\right)$ are quite consistent with the experimental ones, supporting the presented theoretical analysis of the spectrum.

\section{Acknowledgements}

This work was supported by the National University of La Plata and the Consejo Nacional de Investigaciones Científicas y Técnicas (CONICET). 
[1] M. Yu. Zolotov and B. Fegley, Jr., Icarus 133, 293 (1998).

[2] X. Zhang, M. C. Liang, F. P. Mills, D. A. Belyaev, and Y. L. Yung, Icarus 217, 714 (2012).

[3] P. W. Schenk, Z. Anorg. Allg. Chem. 211, 150 (1933).

[4] D. J. Meschi and R. J. Myers, J. Am. Chem. Soc. 78, 6220 (1956)

[5] D. J. Meschi and R. J. Myers, J. Mol. Spectrosc. 3, 405 (1959).

[6] H. Cordes, Z. Physik 105, 251 (1937).

[7] A. V. Jones, J. Chem. Phys. 18, 1263 (1950).

[8] L. F. Phillips, J. J. Smith, and B. Meyer, J. Mol. Spectrosc. 29, 230 (1969).

[9] G. Lakshminarayana, J. Mol. Spectrosc. 55, 141 (1975).

[10] K.-E. J. Hallin, A. J. Merer, and D. J. Milton, Can. J. Phys. 55, 1858 (1977).

[11] P. Hohenberg and W. Kohn, Phys. Rev. B 136, 864 (1964).

[12] D. E. Wong and T. H. Dunning, J. Chem. Phys. 98, 1358 (1993); and references therein.

[13] M. J. Frisch, G. W. Trucks, H. B. Schlegel, G. E. Scuseria, M. A. Robb, J. R. Cheeseman, G. Scalmani, V. Barone, B. Mennucci, G. A. Petersson, H. Nakatsuji, M. Caricato, X. Li, H. P. Hratchian, A. F. Izmaylov, J. Bloino, G. Zheng, J. L. Sonnenberg, M. Hada, M. Ehara, K. Toyota, R. Fukuda, J. Hasegawa, M. Ishida, T. Nakajima, Y. Honda, O. Kitao, H. Nakai, T. Vreven, J. A. Montgomery, Jr., J. E. Peralta, F. Ogliaro, M. Bearpark, J. J. Heyd, E. Brothers, K. N. Kudin, V. N. Staroverov, R. Kobayashi, J. Normand, K. Raghavachari, A. Rendell, J. C. Burant, S. S. Iyen- gar, J. Tomasi, M. Cossi, N. Rega, J. M. Millam, M. Klene, J. E. Knox, J. B. Cross, V. Bakken, C. Adamo, J. Jaramillo, R. Gomperts, R. E. Stratmann, O. Yazyev, A. J. Austin, R. Cammi, C. Pomelli, J. W. Ochterski, R. L. Martin, K. Morokuma, V. G. Zakrzewski, G. A. Voth, P. Salvador, J. J. Dannenberg, S. Dapprich, A. D. Daniels, O. Farkas, J. B. Foresman, J. V. Ortiz, J. Cioslowski, and D. J. Fox, Gaussian 09, Revision A.02, Gaussian Inc., Wallingford CT, 2009.

[14] W.-J. Lo, Y.-J. Wu, and Y.-P. Lee, J. Phys. Chem. A 107, 6944 (2003).

[15] M. J. Frisch, J. A. Pople, and J. S. Binkley, J. Chem. Phys. 80, 3265 (1984); and references therein.

[16] C. J. Cobos and A. E. Croce, Z. Naturforsch. 65a, 720 (2010).

[17] S. S. Leang, F. Zahariev, and M. S. Gordon, J. Chem. Phys. 136, 104101 (2012).

[18] M. Caricato, G. W. Trucks, M. J. Frisch, and K. B. Wiberg, J. Chem. Theory Comput. 6, 370 (2010).

[19] K. Tsukiyama, D. Kobayashi, K. Obi, and I. Tanaka, Chem. Phys. 84, 337 (1984).

[20] Q. Zhang, P. Dupré, B. Grzybowski, and P. H. Vaccaro, J. Chem. Phys. 103, 37 (1995).

[21] T. Müller, P. H. Vaccaro, F. Pérez-Bernala, and F. Iachello, J. Chem. Phys. 111, 5038 (1999).

[22] J. Lindenmayer, H. D. Rudolph, and H. Jones, J. Mol. Spectrosc. 119, 56 (1986); and references therein.

[23] D. J. Clouthier and M. L. Rutherford, Chem. Phys. 127, 189 (1988).

[24] U. Blukis and R. J. Myers, J. Phys. Chem. 69, 1154 (1965). 